\title{
A GESTÃO DA SEGURANÇA DOS ALIMENTOS EM EMPRESA DE SERVIÇO DE ALIMENTAÇÃO E OS PONTOS CRÍTICOS DE CONTROLE DOS SEUS PROCESSOS
}

\author{
GISELE LARA DE ALMEIDA* \\ STELLA REGINA REIS DA COSTA** \\ ARLENE GASPAR ${ }^{\star \star \star}$
}

\begin{abstract}
Este artigo apresenta o diagnóstico do quadro das práticas adotadas na cadeia de produção e fornecimento de alimentos e identifica os pontos críticos de controle dos seus processos, mediante estudo de caso em restaurante comercial. A coleta de evidências ocorreu por meio de observação direta e da documentação. Como instrumental de pesquisa foram usados entrevistas e formulário. Os dados obtidos na aplicação do formulário foram tratados qualitativamente e os obtidos nas entrevistas processados estatisticamente. Os resultados indicaram a higienização inadequada das mãos e a falta de padronização, entre outras, como as práticas mais impactantes na segurança dos alimentos naquela empresa de alimentação. Foram identificados como pontos críticos da rotina, em especial, o controle sobre temperaturas e sobras, bem como a maneira de condução da administração de pessoal.
\end{abstract}

* Mestre em Ciência e Tecnologia de Alimentos pela Universidade Federal Rural do Rio de Janeiro (UFRJ), Seropédica, RJ (e-mail: giselelalmeida@yahoo.com.br).

** Professor titular, UFRJ, Seropédica, RJ (e-mail: stella@ufrrj.br).

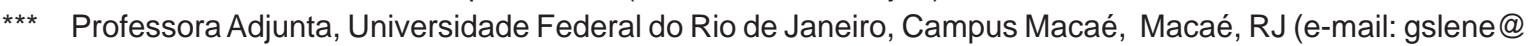
hotmail.com). 


\section{INTRODUÇÃo}

Segundo dados da Associação Brasileira de Refeições Coletivas (ABERC), as empresas nacionais de serviço de alimentação serviram no ano de 2011 mais de 16,5 milhões de refeições/ dia, sendo estimado para 2012 crescimento em torno de 8,7\% (ABERC, 2012). Já a Associação Brasileira de Bares e Restaurantes (ABRASEL) aponta que, há nove anos, a cada R\$100,00 que os brasileiros gastavam com a alimentação, $R \$ 11,00$ eram para comer fora de casa. Em 2011 esse número chegou a $R \$ 12,00$ e no Rio de Janeiro a média alcança $R \$ 37,78$ (ABRASEL, 2012), demonstrando claramente a força desse mercado.

Quando se fala em produção de alimentos é interessante ressaltar que muitas causas de contaminação são provenientes da falta de aplicação de procedimentos de limpeza e do comportamento das pessoas que manipulam os alimentos. No Brasil, a incidência de práticas que comprometem a qualidade do alimento (como a presença de micotoxinas e cadeias-de-frio que não são asseguradas, dentre outras) ainda persistem. Embora exista aumento de empreendimentos direcionados à segurança de alimentos, o setor ainda enfrenta muitos problemas que podem contribuir para o surgimento de doenças de origem alimentar no consumidor. De acordo com o Relatório anual da gerência geral de alimentos da Agência Nacional de Vigilância Sanitária (AGGALI/ ANVISA) foram registrados no Brasil, em 2007, 19.817 casos de surtos de Doenças Transmitidas por Alimentos (DTA) e 21 óbitos (ANVISA, 2006).

O governo exerce papel central no estabelecimento dos padrões de segurança e no controle de alimentos, mas sua estrutura é altamente ineficiente. As esferas federal, estadual e municipal estão desarticuladas e enfatizam ações burocrático-jurídicas e não científicas (ANVISA, 2006). Para Cavalli (2008) não é prática cultural brasileira o controle sobre a qualidade e segurança dos alimentos que são consumidos. A população, em geral, não exerce o direito de fazer qualquer tipo de exigência aos órgãos responsáveis pela fiscalização do exercício da lei, referente à segurança de alimentos.

O Ministério da Saúde (MS), por meio da Agência Nacional de Vigilância Sanitária (ANVISA) e suas agências estaduais e distritais, atua na definição dos procedimentos e padrões de qualidade obrigatórios para a produção de alimentos prontos para consumo (PERETTI, SPEZIA e ARAÚJO, 2008). Dentre as ferramentas disponíveis para a garantia da segurança de alimentos podem ser citadas as Boas Práticas de Fabricação (BPF), os Procedimentos Padrão de Higiene Operacional (PPHO) e o Sistema de Análise de Perigos e Pontos Críticos de Controle (APPCC). Esse último tem sido amplamente recomendado por órgãos de fiscalização e utilizado em toda cadeia produtiva de alimentos por ter como filosofia a prevenção, a racionalidade e a especificidade para controle dos riscos que o alimento possa oferecer, principalmente, no que diz respeito à qualidade sanitária.

Durante a execução do projeto APPCC/Mesa (SENAI, 2008) foram identificadas como dificuldades na implantação de APPCC em unidades de alimentação e nutrição (UAN), os seguintes fatores: sensibilização e importância do APPCC para os empresários; adequação dos formulários; pouco conhecimento na área de microbiologia; entendimento custo $\mathrm{x}$ benefício; adequação do layout; resistência quanto a mudanças nos procedimentos de rotina e a adequação das receitas e cardápios. Essas dificuldades precisam ser vencidas, pois a implementação do sistema APPCC resultaria em redução das Doenças Veiculadas por Alimentos (DVA) e consequentemente em melhoria da saúde pública.

Para Akutsu et al. (2005), a qualidade em unidades de alimentação e nutrição está associada aos aspectos intrínsecos do alimento (qualidade nutricional e sensorial), à segurança (qualidade higiênico-sanitária), ao atendimento (relação cliente-fornecedor) e ao preço. Silva Junior (2005) afirmou que a finalidade do serviço de alimentação não é simplesmente alimentar o homem, mas "bem alimentar o homem".

O fato do quadro de segurança de alimentos das empresas de serviço de alimentação estar distante do considerado ideal requer que esse aspecto seja visto como algo macroscópico e que perigos podem ocorrer em toda e qualquer etapa do processo. Também é fundamental que 
se conheça quais são os principais pontos que impactam a garantia do fornecimento de alimentos seguros para que sejam tratados com rigor e metodologia adequados. Identificar e compreender esses fatores coloca-se como importante eixo de reflexão para o desenvolvimento da motivação e aperfeiçoamento de práticas gerenciais. Além disso, o restaurante que proporciona aos seus clientes a certeza de fornecimento de alimento seguro (de qualidade) tem maiores chances de permanecer e crescer no mercado e assim buscar novos desafios.

Spers (2003) relatou que a produção de alimentos seguros tem crescido em importância, juntamente com os novos processos de industrialização e tendências de comportamento do consumidor. No entanto, de acordo com Silva Junior (2005), apesar da importância que representa para a economia mundial, o segmento de refeições coletivas manteve-se durante muito tempo à margem das evoluções tecnológicas, tanto em termos de equipamentos e instalações, como de organização e gestão de processos.

Este artigo apresenta o diagnóstico do quadro das práticas adotadas na cadeia de produção e fornecimento de alimentos e identifica os pontos críticos de controle dos seus processos, mediante estudo de caso em restaurante comercial.

\section{METODOLOGIA}

A pesquisa foi realizada num restaurante comercial, do tipo self-service, localizado na Zona Sul do estado do Rio de Janeiro. A seleção do estudo de caso ocorreu por conveniência, na qual o pesquisador seleciona membros da população que sejam mais acessíveis (OLIVEIRA, 2001).

As evidências foram obtidas com base no fundamento da triangulação de dados a partir da observação direta intensiva e da documentação direta, na qual foram utilizados como instrumental de pesquisa o formulário e a entrevista semi-estruturada focalizada. Com relação ao formulário, adotou-se check-list de Boas Práticas de Fabricação (BPF) adaptado do modelo elaborado por Castro (2007). Preparou-se a entrevista conforme as diretrizes da metodologia científica laboratorial, apresentadas por Lakatos e Marconi (2008): observação do contato inicial com o entrevistado; formulação (clareza, relevância, validade, especificidade e extensão) das perguntas; o registro das respostas e do término da entrevista.

De acordo com a classificação dada por Yin (2005), esta pesquisa teve como estratégia o estudo de caso único holístico e descritivo.

Foram realizadas 12 inserções na UAN pesquisada, no período de agosto a novembro de 2008, duas das quais serviram para aplicação dos pré-testes. Todos os quinze (15) funcionários da UAN, no devido momento, foram ouvidos.

Os dados coletados mediante formulário e observação direta foram tratados de forma qualitativa por meio da técnica analítica de adequação ao padrão. Este estudo de caso teve como padrões orientativos o Código Internacional de Práticas recomendado pelo Codex Alimentarius, CAC/RCP 1 (FAO/WHO, 2003), os requisitos da NBR ISO 22000:2006 (ABNT, 2006) e os requisitos do Sistema APPCC Mesa do Projeto APPCC/Mesa - CNI/SENAI/SEBRAE (SENAI, 2000). Os dados obtidos mediante aplicação de questionários aos manipuladores foram tabulados em planilha eletrônica e utilizados na confecção das tabelas de frequência simples ou de dupla entrada. Para a avaliação de associação entre as variáveis qualitativas dispostas nas tabelas de contingência, utilizou-se o teste de qui-quadrado $\left(\chi^{2}\right)$ ao nível de $5 \%$ de significância. De acordo com Regazzi e Silva (2010), a igualdade de qualquer subconjunto de parâmetros pode ser verificada por meio do teste da razão de verossimilhança utilizando as aproximações $\mathrm{F}$ ou qui-quadrado.

\section{RESULTADOS E DISCUSSÃO}

Verificou-se a forma como a gestão da segurança dos alimentos foi concebida na empresa de serviços de alimentação e o grau de atendimento aos requisitos legais. Os dados coletados 
mostraram deficiência na gestão dos processos que impactam diretamente na segurança dos alimentos, no seu planejamento e na habilidade de controlar os perigos presentes em cada etapa dos diversos processos que ocorrem regularmente na UAN. Durante o levantamento foi constatado que:

- a preocupação imediata da administração da UAN envolvia o cumprimento dos compromissos contratuais emergentes e diários da empresa para mantê-la funcionando. Além da falta de recursos, outros pontos que impactam fortemente a adoção de planos de segurança de alimentos e a implementação concreta e eficiente dos programas de pré-requisitos foram: a falta de formação em gestão dos proprietários e administradores; pouco conhecimento dos princípios básicos de segurança de alimentos e dos processos de higiene e limpeza; e a ineficácia dos processos de capacitação, motivação e avaliação de desempenho de pessoal;

- o fornecimento de alimentos seguros para a população depende não somente do sistema de gestão adotado para garantia da segurança de alimentos, mas também de fatores como, a cultura da empresa, entendimento sobre segurança de alimentos, visão de melhoria contínua pelos gestores, conhecimento sobre gestão de processos, adoção de programas de pré-requisitos, tratamento estruturado das não conformidades observadas, liderança e planejamento financeiro;

- é fundamental que os empregados que atuam diretamente na elaboração de alimentos estejam convencidos de que fazendo o controle sistematizado das etapas de produção indicadas como pontos críticos de controle haverá diminuição do risco de contaminação do produto.

Pesquisando a segurança de alimentos em restaurantes comerciais, Lourenço e Carvalho (2006) também constataram que a melhoria da qualidade dos serviços inicia-se com a sensibilização e a capacitação da gerência, a qual tem grande responsabilidade sobre a qualidade do alimento fornecido, por meio da tomada de decisões.

Quanto à capacitação de pessoal, Cavalli e Salay (2007) observaram que $79 \%$ dos funcionários de um restaurante comercial não tinham curso profissionalizante, possuíam baixo nível de escolaridade e pouco tempo de experiência, no máximo 5 anos na empresa. Os autores verificaram que a falta de profissionalização do setor dificulta a garantia da segurança de alimentos. Esses resultados confirmam a necessidade de maior atenção aos processos de capacitação, motivação e avaliação de desempenho de pessoal.

\subsection{ATENDIMENTO AOS REQUISITOS DE BPF}

A UAN pesquisada contava com manual de BPF descrito formalmente, porém não era conhecido pelos manipuladores de alimentos e $50 \%$ desses desconhecia o programa de qualidade. Os PPHO não estavam descritos e nem dispostos nas áreas. A UAN não contava com Plano de Riscos e Perigos decorrentes da sua localização.

A área externa apresentava piso irregular e foi verificada a existência de objetos em desuso, como caixas plásticas, e de vetores, como pombos. O acesso à área de produção era direto, ou seja, não comum a outros usos.

Aárea de produção não tinha ventilação, a iluminação era deficiente e o lay-out insatisfatório, com pouco espaço para movimentação de pessoas e materiais. Não havia janelas na área de 
produção e o sistema de exaustão não tornava o ambiente confortável. Pisos, paredes e tetos, apesar do acabamento liso e da cor clara, não estavam em bom estado de conservação. As tampas dos ralos estavam danificadas.

Não havia acompanhamento do estado de saúde do pessoal. Em dez anos de atividade, a UAN ofereceu apenas um curso sobre manipulação de alimentos aos seus funcionários. Dos dez manipuladores de alimentos, quatro assumiram pequena responsabilidade sobre a qualidade dos alimentos servidos e seis afirmaram que suas funções não afetavam a qualidade desses alimentos. De acordo com Silveira et al. (2003), pessoas despreparadas para o desempenho de atividades relacionadas à manipulação de alimentos dificultam sua conservação adequada nos serviços de alimentação. Uma das maneiras de se garantir a qualidade higiênico-sanitária dos alimentos envolve programas de educação continuada para os manipuladores e a realização semestral de exames parasitológicos desses indivíduos, já que representam potenciais transmissores de enteroparasitoses (NOLLA e CANTOS, 2005). Segundo Vanzo e Azevedo (2003), as práticas indevidas de processamento e de higiene por pessoas inabilitadas podem provocar a contaminação cruzada de alimentos, o que contribui para o aumento do risco à saúde do consumidor.

A verificação da qualidade da água e o controle de pragas são realizados por empresa terceirizada, registrada junto ao Ministério da Saúde. Havia registros mensais das inspeções das armadilhas. A higienização dos reservatórios de água e a coleta de amostras para análise de potabilidade também são mensais e os laudos evidenciaram que ambos atendiam aos padrões de sanidade.

A recepção de matéria-prima e ingredientes ocorre em local protegido e isolado da área de produção. Não há controle formal sobre a qualidade da matéria-prima e a verificação baseava-se na data de validade e aspecto do produto. Os produtos são recebidos diariamente e estocados em local adequado, limpo e organizado. A preparação ocorre de forma imediata, sendo respeitado no uso de matéria-prima e ingredientes a ordem de entrada e os prazos de validade dos produtos. Sobras, quando apropriado, eram congeladas e reaproveitadas.

O controle das temperaturas de congelamento e refrigeração ocorria por meio dos termopares dos equipamentos e termômetros colocados em pontos estratégicos. No entanto, não havia registros desse acompanhamento e os instrumentos não passavam por rotina de verificação e calibração padronizada. As temperaturas dos balcões, em especial do balcão quente, também não eram monitoradas.

O lixo era retirado diariamente pelo serviço de coleta municipal, mas as lixeiras não tinham tampa e não estavam forradas com sacos plásticos. Em geral, não havia separação do lixo orgânico.

Quanto aos processos de limpeza e sanitização, os lavatórios da área de produção, apesar de estarem dotados de água quente e em número suficiente para atender a toda a área de produção, não tinham torneiras com acionamento automático. Os detergentes empregados não são aprovados pelo Ministério da Saúde e os panos, superfícies e utensílios são higienizados com álcool 96\%. Equipamentos, móveis e máquinas são lavados semanalmente. Não havia programa estruturado de limpeza e sanitização e nem registros dessas atividades. De acordo com Chesca, Andrade e Martinelli (2003), 90\% dos utensílios de uma UAN de Uberaba (SP), com capacidade para 960 refeições, submetidos à avaliação do grau de contaminação encontravam-se em condições higiênico-sanitárias inadequadas.

Em função do pequeno espaço físico disponível para armazenamento, o processo de compras ocorria diariamente. Não havia cadastro dos fornecedores, nem procedimentos formais descritos para sua seleção e acompanhamento.

Não havia padronização dos procedimentos operacionais das atividades que impactam diretamente sobre a segurança dos alimentos, nem registro dessas atividades. 


\subsection{ADMINISTRAÇÃO DE PESSOAL}

A administração da UAN relatou que as maiores dificuldades com a equipe envolvem as práticas de pessoal e resistências a mudanças. Foram mencionadas também dificuldades no cumprimento do horário de trabalho e no atendimento ao estabelecido quanto às atividades da produção.

A empresa não adota plano de cargos e salários estruturado, o que pode inviabilizar a avaliação de desempenho mais eficiente e concorrer para a realização de processos de seleção menos eficazes. A avaliação de pessoal ocorre de maneira informal pela administradora, com base na observação diária do desempenho dos funcionários. Resultado semelhante foi encontrado por Carvalho, Amorim e Tavares (2004) pesquisando indicadores da qualidade no restaurante da coletividade da Universidade Federal Fluminense (UFF). Verificaram a acomodação do quadro funcional em relação ao seu desempenho, gerado muitas vezes, pelo Plano de Cargos e Salários instável e ineficiente.

O processo de seleção, embora não descrito, baseia-se em critérios claros e prédefinidos, ocorrendo por meio de análise curricular, seguida de entrevistas com a administradora. Além das duas proprietárias, normalmente não há membros da mesma família trabalhando na empresa.

Não havia programa de treinamento estruturado com definição do responsável e com aplicação de avaliação de reação para aqueles que ingressam na empresa. Treinamentos de multi-funcionalidade e de troca de função também são inexistentes. Treinamentos de BPF foram realizados nos últimos dois anos, com $80 \%$ dos funcionários, mas até o momento da pesquisa os manipuladores de alimentos não tinham recebido treinamentos de limpeza e sanitização. Cavalli e Salay (2004) pesquisando restaurantes comerciais em Campinas e em Porto Alegre obervaram que a não aplicação do sistema APPCC e das normas BPF-P, bem como de cursos e treinamentos para os recursos humanos, são fatores que podem dificultar a garantia da segurança do alimento para 0 consumidor.

\subsection{PLANEJAMENTO DA PRODUÇÃO}

Para o planejamento e o controle da produção, os gestores não usavam nenhuma ferramenta. A administração, totalmente empírica, limitava-se ao estudo da montagem do cardápio. Os rendimentos e as perdas da produção não são bem conhecidos e, portanto, não são administrados. Apenas as perdas eram controladas quantitativamente (pesadas), porém sem ações preventivas, como procedimentos de manipulação e preparo descritos e registros de controle para o acompanhamento de tal não conformidade.

A empresa não contava com metodologia estruturada para tratamento de não conformidades. Sob o ponto de vista do gestor, as não conformidades mais frequentes envolviam perdas por sobras. Reclamações e demais manifestações de clientes, mesmo sendo poucas, não eram tratadas de maneira sistêmica. A equipe desconhece a necessidade e a metodologia para identifcar e tratar as causas dos problemas. De acordo com a administradora, as práticas de pessoal seriam as únicas causas dos problemas que ocorreram na produção.

\subsection{PONTOS CRÍTICOS DE CONTROLE (PCC) IDENTIFICADOS}

Foram identificados pontos críticos de controle, tanto na etapa de planejamento quanto de operação das atividades que ocorrem normalmente na UAN. As medidas de controle sugeridas para tais pontos críticos são apresentadas nos Quadros 1 e 2. 


\section{QUADRO 1 - PERIGOS E MEDIDAS DE CONTROLE PARA ALGUNS PCC NO PLANEJAMENTO DO FORNECIMENTO DE ALIMENTOS}

\begin{tabular}{|c|c|c|}
\hline PLANEJAMENTO & PERIGOS I PCC & MEDIDAS DE CONTROLE \\
\hline $\begin{array}{l}\text { Implementação do } \\
\text { Programa BPF }\end{array}$ & $\begin{array}{l}\text { Implementação insatisfatória dos } \\
\text { requisitos de boas práticas }\end{array}$ & $\begin{array}{l}\text { - Conhecer e entender profundamente a } \\
\text { importância de cada requisito de BPF } \\
\text { - Elaborar plano de ação (atribuindo } \\
\text { prazos e responsabilidades) para a } \\
\text { implementação dos requisitos de BPF } \\
\text { - Preparar os responsáveis para a } \\
\text { implementação das ações e acompanhar } \\
\text { o andamento do plano de ação }\end{array}$ \\
\hline Padronização & $\begin{array}{l}\text { Falta de padronização - risco de } \\
\text { contaminação dos alimentos e de } \\
\text { ocorrência de acidentes }\end{array}$ & $\begin{array}{l}\text { - Elaborar fluxogramas das principais } \\
\text { atividades que impactam a segurança de } \\
\text { alimentos } \\
\text { - Verificar se tais atividades são exercidas } \\
\text { de forma a promover a segurança dos } \\
\text { alimentos } \\
\text { - Corrigir e adequar as práticas que } \\
\text { podem levar algum tipo de contaminação } \\
\text { para os alimentos } \\
\text { - Descrever tais atividades e capacitar a } \\
\text { equipe na execução conforme o padrão } \\
\text { descrito }\end{array}$ \\
\hline $\begin{array}{l}\text { Processos de } \\
\text { Melhoria }\end{array}$ & $\begin{array}{l}\text { Reincidência de não } \\
\text { conformidades }\end{array}$ & $\begin{array}{l}\text { - Capacitar a equipe nas ferramentas da } \\
\text { qualidade } \\
\text { - Implementar sistemática eficaz para o } \\
\text { tratamento das atividades que ocorreram } \\
\text { em desacordo com o padrão }\end{array}$ \\
\hline $\begin{array}{l}\text { Gestão de } \\
\text { pessoas }\end{array}$ & $\begin{array}{l}\text { Desempenho insatisfatório da } \\
\text { equipe }\end{array}$ & $\begin{array}{l}\text { - Realizar processo de seleção com base } \\
\text { na formação e capacitação } \\
\text { - Promover treinamentos de capacitação e } \\
\text { reciclagem para a equipe } \\
\text { - Elaborar, divulgar e implementar planos } \\
\text { de melhoria e avaliação de desempenho }\end{array}$ \\
\hline
\end{tabular}

No Quadro 2 são sugeridas ações (medidas de controle) para cada atividade operacional a serem implementadas para controle de PCC, abrindo caminho para a promoção do fornecimento de alimentos seguros. 


\section{QUADRO 2 - MEDIDAS DE CONTROLE PARA ALGUNS PCC NAS ETAPAS DO FORNECIMENTO DE ALIMENTOS}

\begin{tabular}{|c|c|c|}
\hline OPERAÇÃO & PERIGOS I PCC & MEDIDAS DE CONTROLE \\
\hline Recebimento & $\begin{array}{l}\text { Presença de patógenos em } \\
\text { alimentos crus; contaminação } \\
\text { das superfícies; alimentos de } \\
\text { fontes insalubres * }\end{array}$ & $\begin{array}{l}\text { Realizar a seleção e avaliação de } \\
\text { fornecedores; higienizar a área de } \\
\text { recepção dos produtos; controlar a } \\
\text { temperatura dos alimentos no recebimento }\end{array}$ \\
\hline Congelamento & Sobrevivência de patógenos * & Manter temperaturas $<18^{\circ} \mathrm{C}$ \\
\hline Refrigeração & $\begin{array}{l}\text { Contaminação cruzada; } \\
\text { crescimento de patógenos }\end{array}$ & $\begin{array}{l}\text { Manter alimentos perecíveis em } \\
\text { temperaturas }<4^{\circ} \mathrm{C}\end{array}$ \\
\hline $\begin{array}{l}\text { Estoque de não } \\
\text { perecíveis }\end{array}$ & $\begin{array}{l}\text { Ruptura nas embalagens; } \\
\text { umidade alta; venenos } \\
\text { armazenados próximos a } \\
\text { alimentos; presença de vetores; } \\
\text { gotejamento }\end{array}$ & $\begin{array}{l}\text { Controlar os alimentos no estoque; } \\
\text { organizar adequadamente o estoque; } \\
\text { separar alimentos de produtos de limpeza }\end{array}$ \\
\hline Descongelamento & Multiplicação de patógenos & $\begin{array}{l}\text { Manter sob refrigeração a } 4^{\circ} \mathrm{C} \text { para } \\
\text { descongelamento }\end{array}$ \\
\hline Reconstituição & $\begin{array}{l}\text { Contaminação durante a } \\
\text { reidratação; multiplicação } \\
\text { microbiana }\end{array}$ & $\begin{array}{l}\text { Utilizar água potável e somente utensílios } \\
\text { higienizados; consumir imediatamente } \\
\text { o alimento ou refrigerar em pequenas } \\
\text { porções }\end{array}$ \\
\hline Pré-preparo & $\begin{array}{l}\text { Contaminação cruzada dos } \\
\text { alimentos crus; contaminação } \\
\text { pelos equipamentos, utensílios } \\
\text { e mãos dos manipuladores; } \\
\text { multiplicação microbiana }\end{array}$ & $\begin{array}{l}\text { Evitar manipular alimentos crus junto a } \\
\text { alimentos cozidos; evitar tocar os alimentos } \\
\text { que não sofrerão coç̧ão; não ultrapassar o } \\
\text { tempo de } 30 \text { min nesta etapa do processo * }\end{array}$ \\
\hline Cocção & $\begin{array}{l}\text { Sobrevivência de esporos e } \\
\text { patógenos na forma vegetativa }\end{array}$ & $\begin{array}{l}\text { Atingir, no mínimo } 74^{\circ} \mathrm{C} \text { no interior dos } \\
\text { alimentos, ou cozinhar à temperatura de } \\
65^{\circ} \mathrm{C} \text { por } 15 \text { min }\end{array}$ \\
\hline Espera & $\begin{array}{l}\text { Multiplicação microbiana se os } \\
\text { alimentos permanecerem em } \\
\text { temperatura ambiente ou morna } \\
\text { por muito tempo * }\end{array}$ & $\begin{array}{l}\text { Atingir } 55^{\circ} \mathrm{C} \text { na superfície dos alimentos } \\
\text { imediatamente após a cocção }\end{array}$ \\
\hline
\end{tabular}

continua... 
Continuação

\begin{tabular}{|c|c|c|}
\hline OPERAÇÃO & PERIGOS / PCC & MEDIDAS DE CONTROLE \\
\hline $\begin{array}{l}\text { Refrigeração pós- } \\
\text { cocção }\end{array}$ & Multiplicação de patógenos & $\begin{array}{l}\text { Refrigerar os alimentos de } 55^{\circ} \mathrm{C} \text { para } 21^{\circ} \mathrm{C} \\
\text { em } 2 \text { horas e, a seguir, refrigerá-los a } 4^{\circ} \mathrm{C} \\
\text { em } 6 \text { horas * }\end{array}$ \\
\hline Reaquecimento & $\begin{array}{l}\text { Sobrevivência de esporos e de } \\
\text { patógenos na forma vegetativa. } \\
\text { Persistência de toxinas } \\
\text { termoestáveis }\end{array}$ & $\begin{array}{l}\text { Atingir } 74^{\circ} \mathrm{C} \text { no interior dos alimentos; } \\
\text { evitar multiplicação prévia dos } \\
\text { microorganismos nos alimentos }\end{array}$ \\
\hline $\begin{array}{l}\text { Espera para } \\
\text { distribuição }\end{array}$ & $\begin{array}{l}\text { Multiplicação microbiana se os } \\
\text { alimentos permanecerem em } \\
\text { temperatura ambiente ou morna } \\
\text { * }\end{array}$ & $\begin{array}{l}\text { Manter os alimentos à temperatura superior } \\
\text { a } 60^{\circ} \mathrm{C} \text { para que entrem na distribuição no } \\
\text { mínimo a } 60^{\circ} \mathrm{C}\end{array}$ \\
\hline $\begin{array}{l}\text { Distribuição em } \\
\text { balcão aquecido * }\end{array}$ & $\begin{array}{l}\text { Em alimentos mantidos a } \\
\text { temperaturas quentes pode } \\
\text { haver sobrevivência de } \\
\text { microorganismos * }\end{array}$ & $\begin{array}{l}\text { Manter alimentos a } 65-60^{\circ} \mathrm{C} \text { e abaixo de } \\
60^{\circ} \mathrm{C} \text { por apenas } 3 \text { horas. Desprezar os } \\
\text { alimentos que permaneceram além desse } \\
\text { tempo }\end{array}$ \\
\hline $\begin{array}{l}\text { Distribuição em } \\
\text { balcão refrigerado } \\
\text { * }\end{array}$ & $\begin{array}{l}\text { Alimentos mantidos acima } \\
\text { de } 10^{\circ} \mathrm{C} \text { ou em temperatura } \\
\text { ambiente podem provocar a } \\
\text { multiplicação microbiana }\end{array}$ & $\begin{array}{l}\text { Manter alimentos em espera sob } \\
\text { refrigeração à temperatura inferior a } 10^{\circ} \mathrm{C} \text {. } \\
\text { Alimentos em distribuição devem estar a } \\
\text { menos de } 10^{\circ} \mathrm{C} \text { por no máximo } 4 \text { horas } \\
\text { Desprezar alimentos que permaneceram } \\
\text { entre } 10-21^{\circ} \mathrm{C} \text { por } 2 \text { horas e acima de } 21^{\circ} \mathrm{C}\end{array}$ \\
\hline $\begin{array}{l}\text { Higiene de } \\
\text { equipamentos e } \\
\text { utensílios }\end{array}$ & $\begin{array}{l}\text { Equipamentos e utensílios sem } \\
\text { a devida higienização podem } \\
\text { contaminar os produtos * }\end{array}$ & $\begin{array}{l}\text { Utilizar água potável nos processos } \\
\text { de higienização Utilizar detergentes e } \\
\text { sanitizantes apropriados e de acordo com o } \\
\text { tempo e diluição ideais para sua eficácia * }\end{array}$ \\
\hline $\begin{array}{l}\text { Higiene dos } \\
\text { manipuladores * }\end{array}$ & $\begin{array}{l}\text { Manipuladores sem a devida } \\
\text { orientação de lavagem das } \\
\text { mãos são grande foco de } \\
\text { contaminação cruzada * }\end{array}$ & $\begin{array}{l}\text { Dispor de sabonetes bactericidas nos } \\
\text { sanitários e nas áreas de preparação. } \\
\text { Orientar/capacitar os manipuladores na } \\
\text { higiene das mãos * }\end{array}$ \\
\hline $\begin{array}{l}\text { Higiene das frutas } \\
\text { e hortaliças * }\end{array}$ & $\begin{array}{l}\text { Patógenos, ovos e cistos de } \\
\text { parasitas podem persistir * }\end{array}$ & $\begin{array}{l}\text { Lavar em água corrente, imergir em água } \\
\text { clorada a } 150-200 \text { ppm e enxaguar em } \\
\text { água ou vinagre a } 2 \%\end{array}$ \\
\hline
\end{tabular}

Fonte: Adaptação do Sistema APPCC, Codex Alimentarius (FAO/WHO).

* = Dados modificados pelos autores. 


\section{CONCLUSÃO}

Para que as unidades de alimentação e nutrição, em especial os restaurantes comerciais do tipo self-service, possam fornecer alimentos seguros e atender à legislação pertinente à segurança de alimentos é necessário, inicialmente, que as empresas adotem a implantação plena do Programa de BPF e dos PPHO nas rotinas da unidade.

Foram diagnosticadas na UAN avaliada: a higienização inadequada das mãos dos manipuladores, a falta de acompanhamento do estado de saúde dos manipuladores, a aplicação de processos de higiene e limpeza inadequados, a ausência de padronização e a falta de tratamento das não conformidades existentes, como as práticas adotadas pela UAN que mais impactam a segurança alimentar ao longo da cadeia de produção e fornecimento de alimentos.

Os pontos críticos de controle (sobre os quais se faz necessário exercer gestão) identificados na rotina de produção e fornecimento de alimentos foram: controle das temperaturas de armazenamento, de cocção e de distribuição de alimentos; controle das sobras e dos processos de higiene e limpeza. Outro forte ponto crítico de controle identificado no caso estudado envolveu a administração de pessoal, especialmente no tocante à seleção, capacitação, motivação e ao monitoramento do estado de saúde dos manipuladores.

\section{ABSTRACT \\ THE MANAGEMENT OF SAFE FOOD IN A COMMERCIAL RESTAURANT AND THE CRITICAL CONTROL POINTS OF THEIR PROCESS}

The present work presents diagnosis of the practices adopted in food production and supply chain, and identifies critical points in their process control, by a case study performed in a commercial restaurant. The evidence collection was performed by direct observation and documentation. Interviews and forms were used as research tools. The data obtained by the application of the forms was managed qualitatively while those obtained through the interviews were statistically processed. The results indicated inadequate hands hygiene and lack of standardization, among others, as the adopted practices with higher impact over food safety in that food company. Were specially identified as critical points on the routine, the temperature control as well as the manners adopted for staff administration.

KEY-WORDS: COMMERCIAL RESTAURANTS; FOOD SAFETY; CRITICAL CONTROL POINTS.

\section{REFERÊNCIAS}

1 AKUTSU, Rita de Cássia; BOTELHO, Raquel Assunção; CAMARGO, Érika Barbosa; SÁVIO, Karin Eleonora Oliveira; ARAÚJO, Wilma Coelho. Adequação das boas práticas em serviços de alimentação. Revista de Nutrição, Campinas, v. 18, n. 3, p. 419-427, maio/jun. 2005. Disponível em: <http://www.scielo.br/pdf/rn/ v18n3/a13v18n3. pdf>. Acesso em: 18 ago. 2008.

2 Agência Nacional de Vigilância Sanitária (ANVISA). Relatório da Reunião VISA, Controle Sanitário de Alimentos - 2006. Disponível em: <http:// portal.anvisa.gov.br/wps/portal/anvisa/Alimentos/ Publicacao+Alimentos/fd3ed500406daf0d9eefbfb9dbe20263>. Acesso em: 26 fev. 2010.

3 Associação Brasileira das Empresas de Refeições Coletivas (ABERC). Mercado real. Disponível em: http:// www.aberc.com.br/mercadoreal. asp?IDMenu=21> Acesso em: 27 fev. 2012.

4 Associação Brasileira de Bares e Restaurantes (ABRASEL). Comer fora de casa ficou mais caro em 2011. Disponível em: <http://www.abrasel.com.br/ index.php/atualidade/item/5639/>. Acesso em: 27 fev. 2012.

5 Associação Brasileira de Normas Técnicas (ABNT). NBR/ISO 22000 2006: sistemas e gestão da segurança de alimentos - requisitos para qualquer organização na cadeia produtiva de alimentos. Rio de Janeiro, 2006.

6 CARVALHO, Lúcia Rosa de; AMORIM, Sérgio R. Leusin de; TAVARES, Marília Ferreira. Sistema de 
indicadores de qualidade para a área de distribuição de refeições em restaurantes para coletividades. Revista Higiene Alimentar, v. 18, n. 116/117, p. 43-46, 2004. Disponível em: <http://www.scielo.br/scielo. php?script= sci_arttext\&pid=S0100-1965199800 0200008\&nrm=iso\&lng=pt\&tlng=pt\#back>. Acesso em: 02 ago. 2008.

7 CASTRO, Fernanda Travassos de. Restaurantes do tipo self-service: análise dos aspectos sanitários e dos manipuladores de estabelecimentos localizados nos shoppings centers da cidade do Rio de Janeiro - RJ. 2007. 105 f. Dissertação (Mestrado em Ciência e Tecnologia de Alimentos) - Universidade Federal Rural do Rio de Janeiro, Seropédica, 2007.

8 CAVALLI, S. B. Segurança alimentar: a abordagem dos alimentos transgênicos. Revista de Nutrição, v. 14, p. 41-46, 2001. Disponível em: <http://www.scielo.br/ scielo.php? script= sci_arttext\&pid=S141552732001000400007\&lng= en\&n rm=iso>. Acesso em: 18 ago. 2008.

9 CAVALLI, S. B.; SALAY, E. Segurança de alimentos e recursos humanos: estudo exploratório em restaurantes comerciais dos municípios de Campinas, SP e Porto Alegre, RS. Revista Higiene Alimentar, v. 18, n. 126127, p. 29-35, nov.- dez. 2004.

10 CAVALLI, S. B.; SALAY, E. Gestão de pessoas em unidades produtoras de refeições comerciais e a segurança alimentar. Revista de Nutrição, v. 20, n. 6, p. 657-667, nov.-dez. 2007.

11 CHESCA, A.C.M.P.A.; ANDRADE, S.C.B.J.; MARTINELLI, T.M. Equipamentos e utensílios de unidades de alimentação e nutrição: um risco constante de contaminação das refeições. Revista Higiene Alimentar, v. 17 , n. $114 / 115$, p. $20-23$, nov.- dez. 2003. Disponível em: <http://www.higienealimentar.com.br/revista/ ed115/revquadro.htm>. Acesso em: 17 maio 2008.

12 Food and Agriculture Organization/World Health Organization (FAO/WHO). Assuring food safety and quality: guidelines for strengthening national food control systems, 2003. [online] Disponível em: <http:// www.who.int/foodsafety/publications/capacity/en/Englsih_Guidelines_Food_control.pdf>. Acesso em: 18 set. 2007.

13 OLIVEIRA, Tania Modesto Veludo de. Amostragem não probabilística: adequações de situações para uso e limitações de amostragem por conveniência, julgamentos e quotas. Revista Administração Online. v. 2, n. 3, 2001. Disponível em: <http://www.fecap.br/adm_online/art23/tania2.htm>. Acesso em: 17 maio 2008.

14 LAKATOS, Eva Maria; MARCONI, Marina de Andrade. Fundamentos de metodologia científica. 6. ed. São Paulo: Ed. Atlas, 2008. 315 p.

15 LOURENÇO, M.S; CARVALHO, L.R. de. Segurança alimentar: utilização de ferramenta da qualidade para melhorias em um restaurante comercial. In: SIMPÓSIO DE ENGENHARIA DE PRODUÇÃO, SIMPEP, 13., 2006, Bauru. Anais... Bauru, UNESP, 2006. 124 p. Disponível em: < http://www.simpep.feb.unesp.br/anais/ anais_13/artigos/707.pdf>. Acesso em: 17 maio 2008.

16 NOLLA, A. C.; CANTOS, G. A. Relação entre a ocorrência de enteroparasitoses em manipulação de alimentos e aspectos epidemiológicos em Florianópolis, Santa Catarina, Brasil. Cadernos de Saúde Pública, v. 2, n. 21, p. 641-645, maio/abr. 2005. Disponível em: < http:// www. ensp.fiocruz.br/csp/pes.html>. Acesso em: 08 set. 2008

17 PERETTI, A.P.R; SPEZIA, D.S; ARAÚJO, W.M.C. Certificação de qualidade no segmento de food service. Revista Higiene Alimentar, v. 18, n. 121, p. 14-18, jun. 2004. Disponível em: <http://www.higienealimentar. com.br/revista/ed121/ revquadro. htm>. Acesso em: 02 ago. 2008.

18 REGAZZI, A. J; SILVA, C. H. O. Testes para verificar a igualdade de parâmetros e a identidade de modelos de regressão não-linear em dados de experimento com delineamento em blocos casualizados. Revista Ceres, v. 57, n.3, p. 315-320, Viçosa, maio/jun., 2010. Disponível em: <http://www.ceres.ufv.br/CERES/ revistas/ V57N003P19908.pdf> Acesso em: 28.ago 2010.

19 Serviço Nacional de Aprendizagem Industrial (SENAI). Projeto APPCC/Mesa - CNI/SENAI/SEBRAE, 2008. Disponível em: <http://www.alimentos. senai.br/mesa/index_m.htm>. Acesso em: 08 set. 2008.

20 Serviço Nacional de Aprendizagem Industrial (SENAI). Programa de alimentos seguros mesa (PAS Mesa), 2000. Disponível em: <http://www.alimentos. senai.br/mesa/index_m.htm>. Acesso em: 08 set. 2008. 
21 SILVA JUNIOR, Eneo Alves da. Manual de controle higiênico-sanitário em serviços de alimentação. 6. ed. São Paulo: Varela, 2005. 623 p.

22 SILVEIRA, I.A.; OLIVEIRA, E.C.M.; POSSATO, I.P.; GUIMARÃES, L.C.; SANTOS, S.; COELHO, A.E.A.; SANTANTA, B. F. Monitoramento microbiológico das mãos de funcionários de uma cantina universitária na cidade de Lavras - MG. Revista Higiene Alimentar, v. 17, n. 104/105, p. 196-197, 2003.

23 SPERS, Eduardo E. Mecanismos de regulação da qualidade e segurança dos alimentos. 2003. 136 p. Tese (Doutorado em Administração), Faculdade de Administração, Economia e Contabilidade, Universidade Estadual de Campinas, Campinas, 2003.

24 VANZO, S.P.; AZEVEDO, R.V.P. Detecção de staphylococcus aureus em manipuladores de alimentos - perfil de resistência e modelos de antibiograma/ fenotipagem. Revista Higiene Alimentar, v. 17, n. 104/105, p. 215-216, jan.-fev. 2003. Disponível em: <http://www. higienealimentar.com.br/revista/ed105/rev quadro105. htm>. Acesso em: 18 set. 2007.

25 YIN, Robert K. Estudo de caso: planejamento e métodos. 3. ed. Porto Alegre: Bookman, 2005. 212 p. 